\title{
Neuropathologic Correlates of Late-Onset Major Depression
}

\author{
Robert A Sweet*,', Ronald L Hamilton², Meryl A Butters', Benoit H Mulsant',4, Bruce G Pollock', \\ David A Lewis', Oscar L Lopez ${ }^{3}$, Steven T DeKosky ${ }^{3}$ and Charles F Reynolds III' \\ 'Department of Psychiatry, University of Pittsburgh School of Medicine, Pittsburgh, PA, USA; '2Division of Neuropathology, University of Pittsburgh \\ School of Medicine, Pittsburgh, PA, USA; ${ }^{3}$ Department of Neurology, University of Pittsburgh School of Medicine, Pittsburgh, PA, USA; ${ }^{4}$ Geriatric \\ Research, Education, and Clinical Center (GRECC), VA Pittsburgh Health Care System, Pittsburgh, PA, USA
}

\begin{abstract}
Late life major depression (LLMD) is frequently associated with cognitive impairment, and increases the risk for subsequent dementia. Cerebrovascular disease, Alzheimer's disease (AD), and dementia with Lewy bodies (DLB) have all been hypothesized to contribute to this increased risk, though prospective studies have yet to examine these hypotheses with autopsy confirmation of the clinical diagnoses. The aim of this study is to examine the rates of cerebrovascular, AD, and DLB pathology among the first I0 participants in an LLMD brain tissue donation program. Subjects' psychiatric diagnoses and cognitive status were prospectively determined during their participation in clinical research protocols of the Intervention Research Center for Late Life Mood Disorders. After death, final clinical diagnoses were made using all clinical information, while blind to neuropathologic diagnoses. Neuropathologic assessments were conducted blind to final clinical diagnoses. Rates of neuropathology were compared with those in a cohort of subjects with dementia, without a history of LLMD, participating in an Alzheimer Disease Research Center. Seven (70\%) subjects had evidence of onset of a dementia prior to death. LLMD with dementia was significantly associated with a neuropathologic diagnosis of AD. Cerebrovascular disease and DLB pathology were also frequent in the LLMD subjects with dementia, and were found in an LLMD subject without dementia. Rates of AD, DLB, and cerebrovascular disease were similar to those in the comparison subjects. These preliminary findings suggest that $A D$ is the predominant neuropathologic condition in LLMD subjects with dementia. Further assessment of the role of comorbid cerebrovascular disease and comorbid DLB is needed.
\end{abstract}

Neuropsychopharmacology (2004) 29, 2242-2250, advance online publication, 8 September 2004; doi:| 0. I038/sj.npp. I 300554

Keywords: Alzheimer's disease; geriatric psychiatry; depression; late onset; mood disorders; neurodegenerative diseases; Lewy bodies; cerebrovascular disorders

\section{INTRODUCTION}

Late life major depression (LLMD) is one of the most frequent psychiatric syndromes and a major source of excess morbidity and disability in the elderly (Gurland $e t$ al, 1996; Conwell, 1996). Though major depression can cause cognitive symptoms in adults of all ages, the relationship between LLMD and cognitive impairment is particularly complex. Significant cognitive impairment occurs in more than half of LLMD subjects during an episode of depression (Butters et al, 2004). Though these deficits may be improved by treatment, impaired patients' cognitive functioning often does not completely normalize, especially in the areas of memory, executive function and information-processing speed (Butters et al, 2000; Nebes et al, 2003). Even among subjects without measurable cognitive impairment, once their depressive episode remits, subsequent onset of a dementia is frequent (Alexopoulos et al, 1993). Addition-

*Correspondence: Dr RA Sweet, E823, TDH, WPIC, 38I I O'Hara Street, Pittsburgh, PA 15213, USA, Tel: + | 412 246 5323, Fax: + I 4I2 246 5332, E-mail: sweetra@upmc.edu,

www.wpic.pitt.edu/research/sweetlab

Received 26 November 2003; revised and accepted I I May 2004 ally, a history of major depression, without specification of episode-related cognitive impairment, is a risk factor for subsequent onset of dementia (Green et al, 2003). Thus, a diagnosis of LLMD, like one of mild cognitive impairment, may serve to identify a high-risk group that would benefit from initiation of therapies with the goal of delaying or preventing the onset of dementia (Nebes et al, 2003; Butters et al, 2004).

This goal is hampered by the lack of knowledge regarding the neuropathology of dementia subsequent to LLMD. Both cerebrovascular disease and Alzheimer's disease (AD) have been hypothesized to underlie the onset of dementia in LLMD subjects (Alexopoulos et al, 1993; Krishnan and Gadde, 1996; Thomas et al, 2001; O'Brien et al, 2001). It should similarly be noted that recent efforts to refine the clinical definition of dementia with Lewy bodies (DLB) have emphasized major depression, in addition to psychotic symptoms, as a common behavioral manifestation of DLB pathology (McKeith et al, 1999; Lopez et al, 2000c). However, the empiric database examining the neuropathology of LLMD to date has been limited to a cohort without the onset of dementia (Thomas et al, 2001; O'Brien et al, 2001). 
Clearly, resolving whether dementia in LLMD subjects results from $A D, D L B$, or cerebrovascular pathology would be best accomplished by prospective characterization of dementia onset in LLMD subjects, with autopsy confirmation of clinical diagnoses. To address these issues, we established a brain tissue donation program for a cohort of elderly patients who were carefully characterized antemortem with regard to diagnosis, clinical characteristics, neuropsychological functioning, medical comorbidity, treatment response, and illness course (McFarland et al, 2000; Butters et al, 2004). Subjects who agreed to participate were followed prospectively until death. The structure of the brain tissue donation consent process, protocols for brain harvesting, brain dissection, and tissue storage were modeled on those of the University of Pittsburgh Alzheimer Disease Research Center (ADRC) and Conte Center for the Neuroscience of Mental Disorders. We now describe the neuropathologic findings from the first 10 such individuals to undergo brain autopsy. To explore whether rates of $A D$, DLB, or cerebrovascular pathology were altered in LLMD with dementia, findings were contrasted with those of a contemporaneous group of elderly subjects presenting to the ADRC with a diagnosis of a dementia, and without any lifetime history of mood disorder.

\section{METHODS}

\section{Subjects}

All LLMD subjects had consented to be participants in the University of Pittsburgh Mental Health Intervention Research Center for Late Life Mood Disorders (MHIRC/ LLMD) Brain Tissue Donation Program. Participants in the Brain Tissue Donation Program included individuals diagnosed with a mood or anxiety disorder and who had participated in clinical studies affiliated with the MHIRC/ LLMD. A more detailed description of the MHIRC/LLMD Brain Tissue Donation Program recruitment and consent procedures has been previously provided (McFarland et al, 2000). The comparison group of individuals had participated in the ADRC. All research interventions were conducted using protocols approved by the University of Pittsburgh Institutional Review Board.

Diagnostic and clinical assessments for the LLMD subjects were specific to the clinical protocols in which each subject participated while alive. All subjects received a structured psychiatric diagnostic interview using the Structured Clinical Interview for DSM-IV (SCID) (First et al, 1997). All information available from the patient, family members and caregivers, physicians and clinicians was considered when determining diagnoses. In order to obtain a complete ascertainment of all mood and anxiety symptoms, 'skip-outs' were not used for the Mood Disorders and Anxiety Disorders sections of the SCID. For most subjects, the completed SCID form and ratings from the 17-item Hamilton Rating Scale for Depression (HRSD; Hamilton, 1960), the Brief Psychiatric Rating Scale (BPRS; Overall and Gorham, 1962) and the Mini Mental State Exam (MMSE; Folstein et al, 1975) were reviewed at a consensus diagnosis conference involving at least three research psychiatrists and the research staff, held during the subject's participation in the clinical study, to obtain and document information on past and current psychiatric symptoms and lifetime and current Axis I diagnoses according to Diagnostic and Statistical Manual IV (DSM IV) criteria (American Psychiatric Association, 1994).

All LLMD subjects participated in intervention protocols that included an acute treatment phase, and for some protocols a continuation or maintenance phase, during which subjects were evaluated at intervals as specified in these protocols (Reynolds III et al, 1999; Bump et al, 2001; Mulsant et al, 2001a,b). These assessments included the HRSD, BPRS, and MMSE. Additional assessments of cognitive function specific to each protocol included the Mattis Dementia Rating Scale (DRS; Mattis, 1976) and the Executive Interview (EXIT; Royall et al, 1992). Some subjects also received a battery of neuropsychologic tests described in detail elsewhere (Butters et al, 2004). Subjects with evidence of cognitive decline, defined by clinically evident cognitive deterioration and/or a DRS score $\leqslant 130$ after resolution of depression, were referred to the ADRC, where they underwent a diagnostic assessment and neuropsychological test battery which has been described in detail elsewhere (Becker et al, 1994; Lopez et al, 2000b; Sweet et al, 2000). After participation in an intervention protocol, LLMD subjects were re-evaluated annually with the HRSD, BPRS, and MMSE. Those subjects who additionally completed the neuropsychological test battery had these tests repeated.

Of the first 11 participants in the LLMD brain tissue donation program to die, families provided post-mortem consent and brains were harvested from 10 subjects. After death, a final consensus diagnosis conference was held for these 10 subjects, involving at least two research psychiatrists, a research neuropsychologist, and the research staff who treated the subject. Diagnosis of a cognitive disorder was only made when there was evidence for cognitive impairments while mood symptoms were stable in partial or complete remission. Final diagnoses utilized all available clinical data, but were conducted blind to the neuropathologic findings. A summary of the demographic and clinical characteristics of the subjects, and the assessments conducted, is presented in Table 1 .

Comparison subjects were selected from among participants in the ADRC who had autopsy between January 1, 1998 and July 1,2003 . The diagnostic evaluations conducted in ADRC participants have been described previously (Becker et al, 1994; Sweet et al, 2000; Lopez et al, 2000a, b). These evaluations include psychiatric assessment by a research psychiatrist using a semi-structured interview (Mezzich et al, 1989) and the HRSD at the time of initial presentation and annual follow-up assessments. Comparison subjects were restricted to those who were diagnosed with a late-onset dementia, defined by an age of onset greater than or equal to age 60 , and who had no lifetime diagnosis of a mood disorder, that is, no mood disorder or episode preceding, concurrent with, or subsequent to onset of the cognitive disorder.

\section{Brain Autopsy and Fixation}

The brain was removed intact at the time of autopsy, weighed, and examined grossly. The brainstem and cerebellum were removed. The cerebral hemispheres were 
divided in the mid-sagittal line. The right cerebral hemisphere was blocked coronally at $1.0-2.0 \mathrm{~cm}$ intervals and examined for any gross pathology; then, samples were rapidly frozen and stored at $-80^{\circ} \mathrm{C}$. The left hemisphere was reserved for immersion in fixative and sampling for histopathology using a protocol that underwent modification during the interval in which subjects were autopsied. In the first five LLMD subjects (110247, 45751, 110311, 110433, 45685), the left hemisphere was immersed in $10 \%$ buffered formalin for 7-14 days, at which time 1-2 cm coronal slabs were cut through the hemisphere and samples for histopathology (as described below) were removed. In the subsequent LLMD subjects (110380, 114181, 110454, $114296,110309)$, the left hemisphere was blocked coronally at $1.0-2.0 \mathrm{~cm}$ intervals, immersed in ice-cold $4 \%$ paraformaldehyde in phosphate buffer for $48 \mathrm{~h}$, washed in a graded series of sucrose solutions, and stored in an antifreeze solution at $-30^{\circ} \mathrm{C}$ until samples were removed for histopathology. All ADRC subjects underwent the former procedure.

\section{Neuropathologic Characterization}

The coronal slabs from the fixed left hemisphere were visually inspected by a neuropathologist (RLH) and sampled in a protocol based on the anatomic guidelines detailed by the Consortium to Establish a Registry for Alzheimer's Disease (CERAD) (Mirra et al, 1991). The sampled regions of interest included the middle and superior frontal gyri (A), the anterior cingulate gyrus and caudate head (B), the hippocampus at level of lateral geniculate (E) (110247, 45751, 110433, 45685, 110380, 114296) or at its first rostral appearance (R) (110311, $114181,110454,110309)$, substantia nigra (G), inferior parietal cortex $(\mathrm{K})$, superior temporal gyrus $(\mathrm{L})$, primary visual cortex (M), and amygdala and transentorhinal cortex (O). For each region, the determination of from which coronal slab it should be sampled, among those in which the region appeared, was made using a randomization scheme to facilitate future unbiased quantification of the remaining tissue. Other identified lesions were placed in additional cassettes. All sampled regions of interest were paraffinembedded, and sectioned at $6 \mu \mathrm{m}$ for all staining procedures, except Bielschowsky stains which were performed on $8 \mu \mathrm{m}$ sections. A section from all blocks was stained with hematoxylin and eosin. Bielschowsky stains were performed on blocks A, B, E, K, L, M, O, and R. Anti- $\beta$ A4 peptide stains were performed on blocks A, B, E, O, and R. Anti-ubiquitin and anti-alpha-synuclein immunolabeling was performed on blocks A, B, G, K, L, M, and O to detect Lewy bodies. Sections were also evaluated for spongiosis, neuronal loss, gliosis, or other lesions, and for determination of Braak Stage (Braak and Braak, 1995). $\beta$ A4 staining confirmed the presence of beta-A4 amyloid deposits in the brain. Neuritic plaques and neurofibrillary tangles were semiquantitatively scored per CERAD criteria (Mirra et al, 1991).

Vascular pathology was evaluated in all cases in several ways, including: (1) visual inspection of the severity of atherosclerosis in large cerebral arteries; (2) semiquantitative rating of the proportion of white matter blood vessels showing amyloid angiopathy in $\beta$ A4 immunostained sections from block A; (3) recording of the number, location, and size of grossly visible infarcts; and, (4) detection of microscopic gray matter infarcts. These evaluations were supplemented with semiquantitative ratings of the severity of perivascular rarefaction, hypertensive vasculopathy, and white matter pallor. Hypertensive vasculopathy, perivascular rarefaction, and diffuse white matter pallor were assessed on the hematoxylin and eosin-stained section of block A containing white matter of the centrum semi-ovale at the level of the head of the caudate nucleus. Hypertensive vasculopathy was defined by fibrosis of small- and mediumsized vessels in the white matter, and was considered mild when less than approximately $10 \%$ of vessels were affected, moderate when $10-75 \%$ of vessels were affected, and severe when $>75 \%$ of vessels were affected. Perivascular rarefaction was defined by widening of the perivascular spaces around the vessels in the white matter without significant reactive gliosis or numerous foamy macrophages. A large perivascular space was defined as greater than the diameter of the blood vessel. Perivascular rarefaction was considered mild when less than approximately $10 \%$ of vessels were affected by small to medium increases in the perivascular space, moderate when $10-50 \%$ of vessels were so affected or up to $20 \%$ of vessels had large perivascular spaces, and severe in cases exceeding moderate. Diffuse white matter pallor was assessed by comparing the tinctorial staining properties of the deep white matter relative to the surrounding cortical gray matter. Diffuse white matter pallor was considered mild when staining was diminished but still darker than the surrounding gray matter, moderate when staining intensity was similar to the surrounding gray matter, and severe when staining intensity was less than that of the surrounding gray matter. As assessments of perivascular rarefaction, hypertensive vasculopathy, and white matter pallor were recently implemented, they were not available for all subjects, but were completed for all LLMD cases and the subset of ADRC cases matched on dementia duration.

Following upon the neuropathologic assessment described above, both clinical neuropathologic diagnoses and research neuropathologic diagnoses were generated. For LLMD subjects, these diagnoses were made blind to the final clinical diagnoses. Diagnostic criteria for Alzheimer Disease were as per CERAD (Mirra et al, 1991). Diagnostic criteria and scoring of Dementia with Lewy Bodies was as per the consensus guidelines for the clinical and pathologic diagnosis of dementia with Lewy bodies criteria (McKeith et al, 1996).

\section{Statistical Analyses}

All analyses were conducted using SPSS (SPSS Inc., 1999). Comparisons of rates of $\mathrm{AD}, \mathrm{DLB}$, and cerebrovascular disease pathology between LLMD subjects with and without subsequent dementia used Fisher's exact test. Comparisons of rates of these pathologies between LLMD and ADRC subjects used Chi-Square and Fisher's exact test as appropriate. Analysis of variance was used to compare ratings of the severity of neocortical neuritic plaque, neurofibrillary tangle, and vascular pathology between LLMD and ADRC subjects diagnosed with AD. 
Table I Demographic and Clinical Characteristics of LLMD Subjects

\begin{tabular}{|c|c|c|c|c|c|c|c|c|c|c|c|}
\hline \# & $\begin{array}{l}\text { Age at } \\
\text { study } \\
\text { entry }\end{array}$ & Race & Sex & $\begin{array}{l}\text { Clinical diagnoses } \\
\text { at study entry }\end{array}$ & Source & $\begin{array}{l}\text { Duration of } \\
\text { follow-up } \\
\text { (months) }\end{array}$ & $\begin{array}{l}\text { Assessments } \\
\text { conducted }\end{array}$ & Post-mortem consensus diagnosis & $\begin{array}{l}\text { Lifetime } \\
\text { duration } \\
\text { (weeks) }\end{array}$ & $\begin{array}{l}\text { Onset } \\
\text { age }\end{array}$ & $\begin{array}{l}\text { Cognitive } \\
\text { domains } \\
\text { impaired }\end{array}$ \\
\hline $110380^{\mathrm{a}}$ & 81 & C & $\mathrm{F}$ & $\begin{array}{l}\text { MDD recurrent, severe } \\
\text { w/psychotic features }\end{array}$ & SCID & 72 & $\begin{array}{l}\text { HRSD } \\
\text { BPRS } \\
\text { MMSE } \\
\text { CDR }\end{array}$ & $\begin{array}{l}\text { MDD recurrent, unspecified } \\
\text { Dementia of Alzheimer's type w/depressed } \\
\text { mood_late onset }\end{array}$ & $\begin{array}{c}520 \\
60\end{array}$ & $\begin{array}{l}77 \\
85\end{array}$ & $\begin{array}{l}\text { Memory } \\
\text { Language } \\
\text { Executive } \\
\text { Attention }\end{array}$ \\
\hline 110247 & 79 & C & $\mathrm{F}$ & $\begin{array}{l}\text { MDD recurrent, moderate, } \\
\text { w/melancholic features }\end{array}$ & $\begin{array}{l}\text { Consensus } \\
\text { SCID }\end{array}$ & 15 & $\begin{array}{l}\text { HRSD } \\
\text { BPRS } \\
\text { DRS } \\
\text { MMSE } \\
\text { Exit }\end{array}$ & $\begin{array}{l}\text { MDD recurrent, full remission } \\
\text { Dementia disorder NOS }\end{array}$ & $\begin{array}{l}1821 \\
334\end{array}$ & $\begin{array}{l}46 \\
74\end{array}$ & $\begin{array}{l}\text { Memory } \\
\text { Visuospatial } \\
\text { Executive } \\
\text { Psychomotor }\end{array}$ \\
\hline$|14| 8 \mid$ & 96 & C & $\mathrm{F}$ & $\begin{array}{l}\text { Bipolar I disorder, manic, } \\
\text { severe, w/psychotic features } \\
\text { GAD } \\
\text { Specific phobia (flying, heights) }\end{array}$ & $\begin{array}{l}\text { Consensus } \\
\text { SCID }\end{array}$ & 18 & $\begin{array}{l}\text { HRSD } \\
\text { YMRS } \\
\text { MMSE } \\
\text { DRS }\end{array}$ & $\begin{array}{l}\text { Bipolar I disorder, full remission } \\
\text { Dementia disorder NOS } \\
\text { GAD } \\
\text { Delirium (GMC-pneumonia) } \\
\text { Specific phobia (flying, heights) }\end{array}$ & $\begin{array}{c}108 \\
54 \\
104 \\
5 \\
3484\end{array}$ & $\begin{array}{l}95 \\
96 \\
95 \\
97 \\
30\end{array}$ & $\begin{array}{l}\text { Memory } \\
\text { Visuospatial } \\
\text { Executive } \\
\text { Attention }\end{array}$ \\
\hline \multirow[t]{2}{*}{ | 10454} & \multirow[t]{2}{*}{93} & \multirow[t]{2}{*}{ C } & \multirow[t]{2}{*}{$\mathrm{F}$} & \multirow{2}{*}{$\begin{array}{l}\text { MDD single episode, } \\
\text { moderate }\end{array}$} & \multirow{2}{*}{$\begin{array}{l}\text { Consensus } \\
\text { SCID }\end{array}$} & \multirow[t]{2}{*}{49} & \multirow{2}{*}{$\begin{array}{l}\text { HRSD } \\
\text { BPRS } \\
\text { DRS } \\
\text { MMSE } \\
\text { CDR }\end{array}$} & \multirow{2}{*}{$\begin{array}{l}\text { MDD single episode, full } \\
\text { remission } \\
\text { Dementia of Alzheimer's type w/ } \\
\text { Delusions_late onset }\end{array}$} & 276 & 92 & \multirow{2}{*}{$\begin{array}{l}\text { Memory } \\
\text { Executive } \\
\text { Attention }\end{array}$} \\
\hline & & & & & & & & & 276 & 92 & \\
\hline \multirow[t]{3}{*}{$45751^{\mathrm{a}}$} & \multirow[t]{3}{*}{79} & \multirow[t]{3}{*}{ C } & \multirow[t]{3}{*}{$\mathrm{F}$} & \multirow[t]{3}{*}{$\begin{array}{l}\text { MDD recurrent, moderate, } \\
\text { w/melancholic features }\end{array}$} & \multirow[t]{3}{*}{$\begin{array}{l}\text { Consensus } \\
\text { SCID }\end{array}$} & \multirow[t]{3}{*}{88} & \multirow[t]{3}{*}{$\begin{array}{l}\text { HRSD } \\
\text { BPRS }\end{array}$} & \multirow{3}{*}{$\begin{array}{l}\text { MDD recurrent, moderate, w/melancholic } \\
\text { Fx } \\
\text { Dementia of Alzheimer's type w/ } \\
\text { delusions-late onset } \\
\text { Psychotic disorder due to dementia and } \\
\text { major depression w/hallucinations }\end{array}$} & & 74 & \multirow[t]{3}{*}{$\begin{array}{l}\text { Memory } \\
\text { Language }\end{array}$} \\
\hline & & & & & & & & & 45 & 85 & \\
\hline & & & & & & & & & 78 & 84 & \\
\hline \multirow[t]{2}{*}{$\left.|103|\right|^{\mathrm{a}}$} & \multirow[t]{2}{*}{72} & \multirow[t]{2}{*}{ C } & \multirow[t]{2}{*}{ M } & \multirow[t]{2}{*}{$\begin{array}{l}\text { MDD single episode, moderate } \\
\text { Dysthymic disorder } \\
\text { Cognitive disorder NOS }\end{array}$} & \multirow[t]{2}{*}{$\begin{array}{l}\text { Consenus } \\
\text { SCID }\end{array}$} & \multirow[t]{2}{*}{68} & \multirow{2}{*}{$\begin{array}{l}\text { HRSD } \\
\text { BPRS } \\
\text { DRS } \\
\text { MMSE } \\
\text { CDR } \\
\text { Exit }\end{array}$} & \multirow{2}{*}{$\begin{array}{l}\text { MDD recurrent, unspecified } \\
\text { Dementia of Alzheimer's type - late onset } \\
\text { Psychotic disorder due to AD w/ } \\
\text { hallucinations } \\
\text { Possible dementia with Lewy bodies } \\
\text { Dysthymic disorder }\end{array}$} & $\begin{array}{l}388 \\
128\end{array}$ & $\begin{array}{l}71 \\
76\end{array}$ & \multirow{2}{*}{$\begin{array}{l}\text { Memory } \\
\text { Language } \\
\text { Visuospatial } \\
\text { Attention }\end{array}$} \\
\hline & & & & & & & & & $\begin{array}{l}84 \\
108 \\
855\end{array}$ & $\begin{array}{l}76 \\
76 \\
62\end{array}$ & \\
\hline \multirow[t]{2}{*}{110433} & \multirow[t]{2}{*}{81} & \multirow[t]{2}{*}{ C } & \multirow[t]{2}{*}{$\mathrm{F}$} & $\begin{array}{l}\text { MDD recurrent, severe } \\
\text { w/psychotic features }\end{array}$ & SCID & 50 & $\begin{array}{l}\text { HRSD } \\
\text { BPRS }\end{array}$ & $\begin{array}{l}\text { MDD recurrent, severe w/psychotic } \\
\text { features }\end{array}$ & 416 & 78 & $\begin{array}{l}\text { Memory } \\
\text { Visuospatial }\end{array}$ \\
\hline & & & & & & & $\begin{array}{l}\text { MMSE } \\
\text { CDR }\end{array}$ & Dementia disorder NOS & 208 & 82 & Attention \\
\hline 114296 & 82 & C & $\mathrm{F}$ & MDD single episode, mild & $\begin{array}{l}\text { Consensus } \\
\text { SCID }\end{array}$ & 7 & $\begin{array}{l}\text { HRSD } \\
\text { MMSE } \\
\text { DRS } \\
\text { Exit } \\
\text { CDR }\end{array}$ & $\begin{array}{l}\text { MDD single episode, mild } \\
\text { Amnestic disorder NOS }\end{array}$ & $\begin{array}{l}158 \\
28\end{array}$ & $\begin{array}{l}80 \\
82\end{array}$ & Memory \\
\hline 110309 & 68 & C & $\mathrm{F}$ & $\begin{array}{l}\text { MDD single episode, moderate } \\
\text { Dysthymic disorder }\end{array}$ & $\begin{array}{l}\text { Consensus } \\
\text { SCID }\end{array}$ & 64 & $\begin{array}{l}\text { HRSD } \\
\text { BPRS } \\
\text { MMSE } \\
\text { DRS } \\
\text { CDR } \\
\text { Exit }\end{array}$ & $\begin{array}{l}\text { MDD recurrent, unspecified } \\
\text { Psychotic disorder NOS } \\
\text { Dysthymic disorder }\end{array}$ & $\begin{array}{l}312 \\
50 \\
728\end{array}$ & $\begin{array}{l}68 \\
50 \\
60\end{array}$ & None \\
\hline 45685 & 75 & C & $\mathrm{F}$ & MDD recurrent, unspecified & SCID & 89 & $\begin{array}{l}\text { SCID } \\
\text { HRSD } \\
\text { MMSE } \\
\text { CDR }\end{array}$ & MDD recurrent, unspecified & 468 & 73 & Visuospatial $^{\mathrm{b}}$ \\
\hline Mean (SD) & $80.6(8.6)$ & & & & & $52.0(29.9)$ & & LLMD & 556.6 & 74.9 & \\
\hline & & & & & & & & Dementia & $\begin{array}{l}(37.4) \\
159.5 \\
(144.6)\end{array}$ & $\begin{array}{r}(13.9) \\
80.9 \\
(12.9)\end{array}$ & \\
\hline
\end{tabular}

${ }^{a}$ Indicates subjects also evaluated for cognitive impairment at ADRC. $\quad{ }^{b}$ Acute CHF at time of assessment. 


\section{RESULTS}

Demographic and clinical characteristics of the LLMD subjects are summarized in Table 1 . Nine of the 10 LLMD subjects received an initial clinical diagnosis of major depression, with one subject diagnosed with bipolar illness. All subjects had first onset of mood disorder in late life. One subject (\#6) received an initial clinical diagnosis of major depression single episode, moderate without psychotic features. In this subject, though some evidence of cognitive impairment was present at the time of initial assessment $(\mathrm{MMSE}=23)$, it was attributed to major depression and no additional cognitive diagnosis was given. At the postmortem consensus diagnostic conference for this subject, after reviewing the entire course of mood disorder and cognitive decline, it was determined that these earlier cognitive symptoms were the initial symptoms of dementia of the Alzheimer's type. In addition to this subject, six additional subjects received a post-mortem consensus diagnosis of a dementia, and one subject was diagnosed with amnestic disorder. Two subjects had no clinical evidence of any cognitive disorder.

The duration of longitudinal follow-up in these subjects from initial study entry to the time of death ranged from 7 to 89 months (median 57 months). One subject (114181) had an unspecified cerebral ischemic event. Several subjects demonstrated mild to moderate extrapyramidal symptoms of tremor (110247, 114181,110454, 45751, 110311, 114296, $110309)$, hypokinesia $(110454,114296)$, or rigidity $(114181$, 110311) at some point during follow-up. Two subjects developed a psychotic disorder characterized by visual hallucinations $(45751,110311)$.

Neuropathologic diagnoses for the 10 LLMD subjects are summarized in Table 2 . AD pathology was present in six $(60 \%)$ subjects. Lewy Body pathology was present in five $(50 \%)$ subjects, including three of the seven subjects with extrapyramidal symptoms, and the two subjects with visual hallucinations. Strokes were present in four (40\%) subjects, including the one with a history of a cerebral ischemic event. Evidence of vascular changes other than stroke was limited in the LLMD subjects. One subject (110247) had severe hypertensive vasculopathy, with mild diffuse white matter pallor, perivascular rarefaction, and amyloid angiopathy. Subject 110380 had severe amyloid angiopathy in conjunction with mild hypertensive vasculopathy. Subject 110454 had moderate hypertensive vasculopathy, with mild amyloid angiopathy. No other subjects had more than mild scores on any of these measures. No patients had evidence of mesial temporal sclerosis, and no subjects had evidence of any other neurodegenerative disorder. Of interest, Lewy body pathology was present in one subject without a clinical diagnosis of any cognitive disorder (subject \#10, Figure 1). The distribution of Lewy body pathology in this subject was also somewhat atypical, with sparse pathology of the substantia nigra, dorsal raphe nucleus, and amygdala, and more severe involvement of the nucleus basalis of Meynert.

When considering the 7/10 LLMD subjects with a clinical diagnosis of a dementia, six (86\%) had AD pathology, DLB was present in four (57\%), and four (57\%) had cerebrovascular pathology. Even in this small sample, the association between a clinical diagnosis of dementia and the presence of $\mathrm{AD}$ pathology was significant (exact $p=0.03$ ). In contrast,

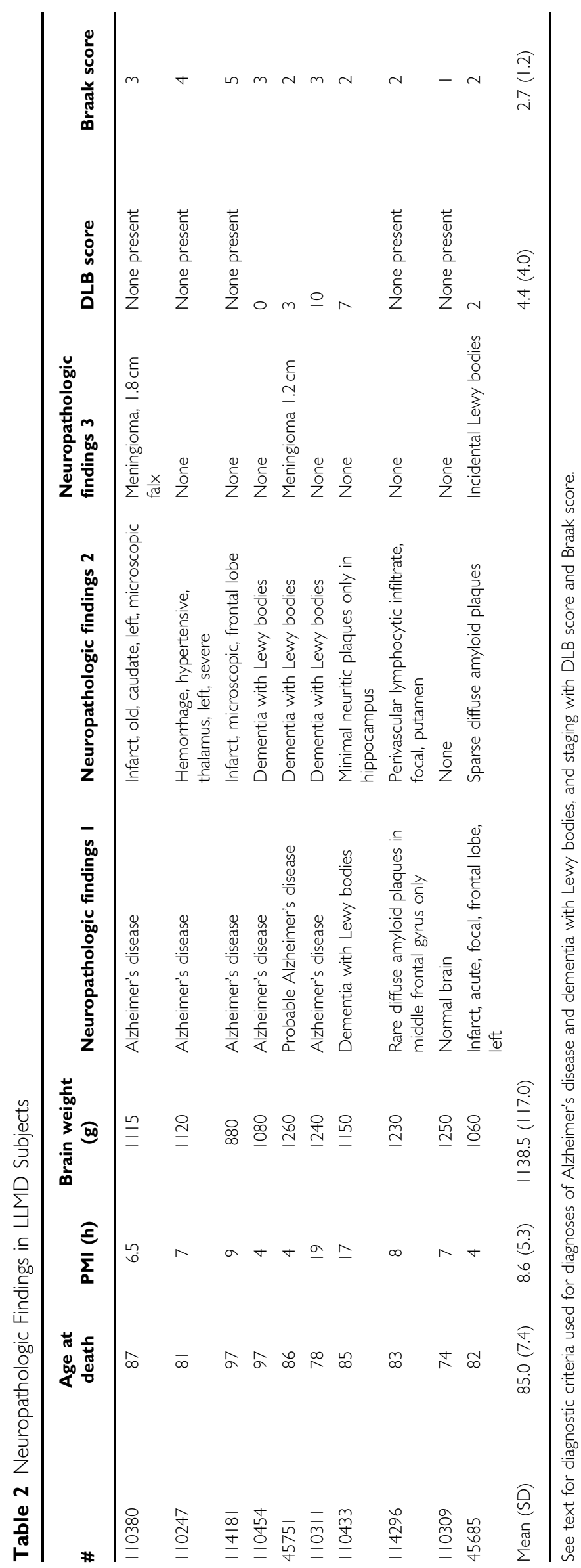




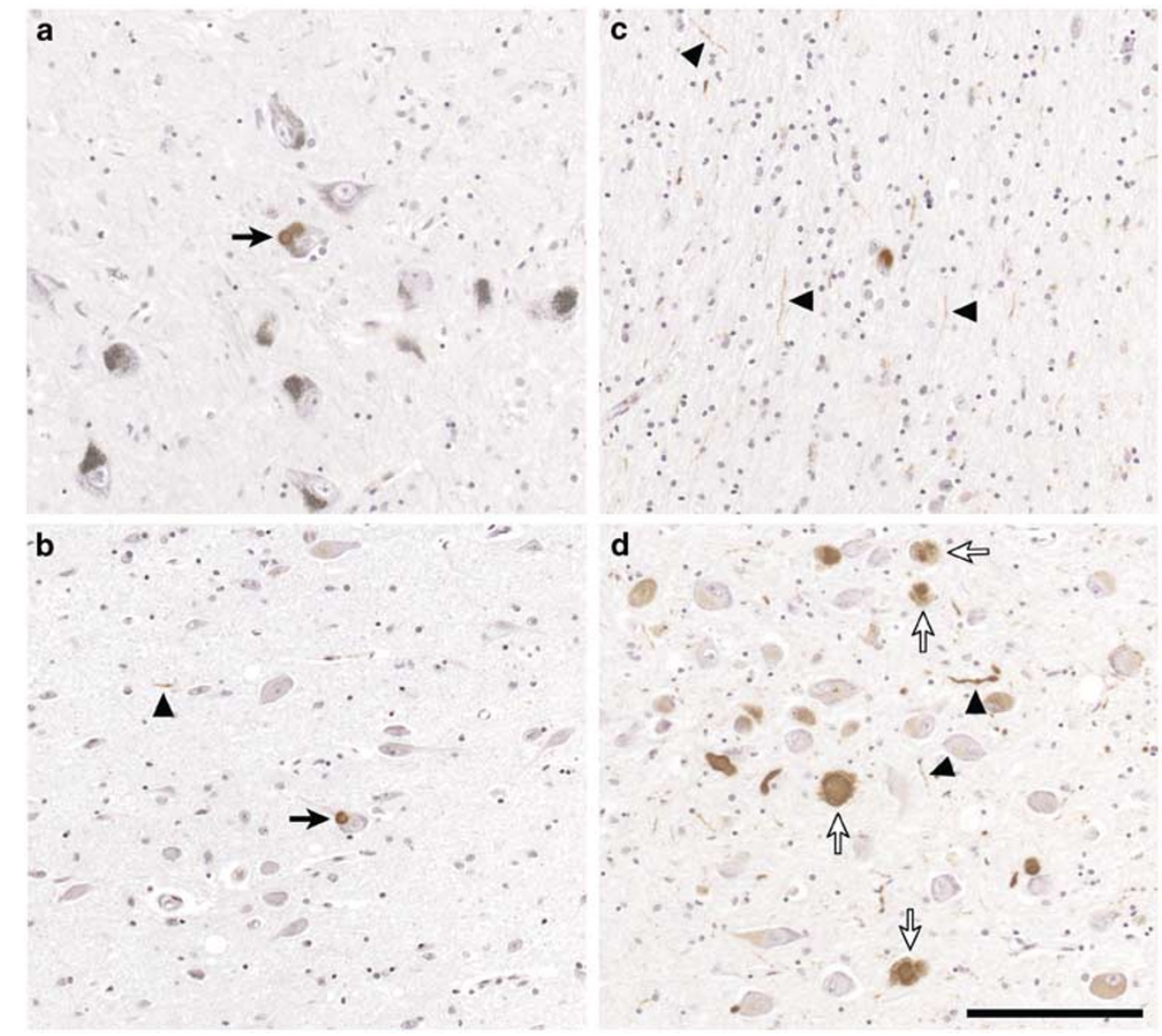

Figure I Photomicrographs of distribution of Lewy body pathology in an LLMD subject without cognitive impairment (subject \# I0). Note the atypical pattern: sparse pathology of the substantia nigra (a), dorsal raphe nucleus (b), and amygdala (c), with more severe involvement of the nucleus basalis of Meynert (d). Solid arrows indicate Lewy bodies, arrowheads indicate neurites containing alpha-synuclein aggregates. These include both fine (b and c) and large-diameter (d) processes. Open arrows indicate intracellular aggregates of alpha-synuclein without the classic halo appearance of Lewy bodies. Scale bar $=150 \mu \mathrm{m}$.

neither DLB nor cerebrovascular pathology frequency differed significantly between LLMD subjects with and without dementia (exact $p=0.6$ and 1.0 , respectively).

A total of 56 ADRC subjects met our criteria for inclusion as comparison subjects. Mean (SD) age at death of the ADRC subjects was $81.2(6.8)$, not significantly different from LLMD subjects (85.1 (7.4), $\left.\mathrm{F}_{1}=2.8, p=0.1\right)$. In all, 28 $(50 \%)$ of ADRC subjects were male, a significantly higher frequency than the LLMD subjects $\left(\chi_{1}^{2}=5.5, p=0.02\right)$. Nearly all (96\%) ADRC subjects were Caucasian, which did not differ from the LLMD group (exact $p=1.0$ ). The mean duration of dementia in the ADRC cohort was 499 (201) weeks, significantly longer than in the seven LLMD subjects with dementia (LLMD $\left.=158(116), \mathrm{F}_{1}=19.1, p<0.001\right)$.

The neuropathologic diagnoses for the ADRC subjects are shown in Table 3. The rate of AD pathology did not differ significantly from the rate of $\mathrm{AD}$ in the LLMD subjects with subsequent dementia, though this rate was significantly higher than in the total LLMD group. No other neuropathologic process differed in frequency between the ADRC and LLMD subjects. Among LLMD subjects with $\mathrm{AD}$, comorbid DLB or cerebrovascular disease was present in $100 \%$, slightly, though nonsignificantly, higher than the rate of $84 \%$ in the ADRC subjects with AD.
As $\mathrm{AD}$ was the predominant neuropathology in LLMD subjects with dementia, we compared the severity of neuritic plaques and neurofibrillary tangles pathology in the LLMD subjects with AD with that found in the 50 ADRC subjects with a neuropathologic diagnosis of $\mathrm{AD}$, to determine whether these features were differentially expressed in the LLMD subjects with dementia. Mean (SD) neuritic plaque scores in the LLMD subjects with $\mathrm{AD}$ were 4.3 (1.0), 4.3 (1.0), 4.0 (1.1), 4.0 (1.1), and $2.0(2.0)$ in the entorhinal cortex, middle frontal gyrus, inferior parietal cortex, superior temporal gyrus, and occipital cortex, respectively. The corresponding values in ADRC subjects were 4.8 (0.74), 4.8 (0.77), 4.6 (1.1), 4.7 (0.91), and 4.3 (1.4). Only the neuritic plaque scores in the occipital cortex differed significantly between groups $\left(F_{1}=12.5, p=0.001\right)$. Mean (SD) neurofibrillary tangle scores in the LLMD subjects with dementia were 4.3 (1.0), 1.2 (1.9), 1.2 (1.5), $1.5(1.8)$, and $0(0)$ in the entorhinal cortex, middle frontal gyrus, inferior parietal cortex, superior temporal gyrus, and occipital cortex, respectively, with corresponding values in ADRC subjects of 4.6 (1.1), 3.8 (1.8), 4.0 (1.8), 4.1 (1.7), and 1.9 (1.9). Scores in the middle frontal gyrus, inferior parietal cortex, superior temporal gyrus, and occipital cortex differed significantly between groups $\left(\mathrm{F}_{1}=11.8\right.$, 
Table 3 Neuropathologic Diagnoses in 56 ADRC Participants

\begin{tabular}{|c|c|c|c|c|c|}
\hline \multirow{2}{*}{$\begin{array}{l}\text { Neuropathologic } \\
\text { diagnosis }\end{array}$} & \multirow[b]{2}{*}{$N(\%)$} & \multicolumn{2}{|c|}{ Comparison with all LLMD } & \multicolumn{2}{|c|}{$\begin{array}{c}\text { Comparison with LLMD dementia } \\
\text { subjects }\end{array}$} \\
\hline & & Test & $p$ & Test & $p$ \\
\hline Alzheimer's disease & $50(89.3)$ & $\chi_{1}^{2}=5.7$ & 0.02 & $\chi_{1}^{2}=0.08$ & 0.8 \\
\hline Dementia with Lewy bodies & $33(58.9)$ & $\chi_{1}^{2}=0.3$ & 0.6 & Fisher's exact & 1.0 \\
\hline Cerebrovascular disease & $25(44.6)$ & $\chi_{1}^{2}=0.07$ & 0.8 & Fisher's exact & 1.0 \\
\hline $\begin{array}{l}\text { Other neurodegenerative } \\
\text { disorder }^{a}\end{array}$ & $5(8.9)$ & $\chi_{1}^{2}=1.0$ & 0.3 & Fisher's exact & 1.0 \\
\hline
\end{tabular}

Note that the subjects may have received more than one diagnosis.

aTwo subjects were diagnosed with motor neuron disease inclusion dementia. One subject each was diagnosed with frontotemporal dementia, progressive supranuclear palsy, and atypical dementia.

$p=0.001 ; \mathrm{F}_{1}=13.4, p=0.001 ; \mathrm{F}_{1}=12.2, p=0.001 ; \mathrm{F}_{1}=5.8$, $p=0.02)$.

As these differences in severity might result from the significantly different durations of dementia in the LLMD and ADRC subjects with $\mathrm{AD}$, we re-examined these severity scores, limiting the ADRC subjects to those with a duration of dementia less than or equal to the longest duration observed in the LLMD subjects (334 weeks). The mean duration of dementia in these 11 ADRC subjects was 255 (72) weeks, though still significantly longer than in the LLMD subjects $\left(\mathrm{F}_{1}=5.0, p<0.04\right)$. Only the difference in severity in neuritic plaques in occipital cortex remained significant $\left(\mathrm{ADRC}=4.0(1.6), \mathrm{F}_{1}=5.1, p=0.04\right)$. We also completed assessments of hypertensive vasculopathy, diffuse white matter pallor, perivascular rarefaction, and amyloid angiopathy for these 11 subjects. Severity scores for these vascular pathologies did not differ between the ADRC subjects and the LLMD subjects, though there was a trend towards less severe amyloid angiopathy in the LLMD subjects $\quad\left(\mathrm{LLMD}=0.6 \quad(1.0), \quad \mathrm{ADRC}=1.6 \quad(1.3), \mathrm{F}_{1}=4.3\right.$, $p=0.052$; all other $p>0.4)$. When considering only the LLMD subjects with $\mathrm{AD}$, none of the comparisons approached significance (all $p>0.3$ ).

\section{DISCUSSION}

To our knowledge, this is the first study to characterize neuropathologic diagnoses in a group of LLMD subjects with dementia. We found that 6/7 LLMD subjects with dementia met neuropathologic criteria for a diagnosis of $\mathrm{AD}$. Of the LLMD subjects without a dementia, the one subject to demonstrate mild neuritic plaque pathology in the hippocampus, not sufficient for a neuropathologic diagnosis of $\mathrm{AD}$, had evidence of mild cognitive impairment and was diagnosed clinically with an amnestic disorder. The association between $\mathrm{AD}$ neuropathologic changes and dementia in the LLMD subjects was significant, though it should be interpreted cautiously due to limitations of the small sample. Similarly, rates of $\mathrm{AD}$ were high and not significantly different between LLMD subjects with dementia and dementia subjects without a history of mood disorder. Postmortem evidence of cerebrovascular pathology and DLB were also common in LLMD subjects, though their frequencies did not significantly differ from those observed in the dementia comparison group without a history of mood disorder.

Clearly, the present study is limited by the small sample size, and must be seen as preliminary in nature. Strengths of the study, however, include the availability of prospective research diagnoses of mood disorders for all subjects, and the longitudinal follow-up with identification of onset of dementia. In this regard, it is important to note that because LLMD subjects were evaluated during and after participation in treatment studies, the clinical determination of dementia presence could be made at a time when mood symptoms were absent or minimal. An important additional strength of the neuropathologic assessments was the use of antibodies directed against alpha-synuclein to detect the presence of Lewy bodies, as it appears to be more sensitive than reliance on hematoxylin and eosin staining, or on labeling with antibodies to ubiquitin (Hamilton, 2000).

A number of studies have found an association of LLMD with an increased risk of clinically diagnosed AD (Kral and Emery, 1989; Jorm et al, 1991; Kokmen et al, 1991; Alexopoulos et al, 1993; van Duijn et al, 1994; Speck et al, 1995; Devanand et al, 1996; Green et al, 2003). Though autopsy confirmation is seen as the 'gold standard' for AD diagnosis, in most clinical research settings a clinical diagnosis of $\mathrm{AD}$ is an excellent proxy, with autopsy confirmation rates generally reported between 85 and $100 \%$ (Becker et al, 1994; Gearing et al, 1995; Lopez et al, 2000a, b). Thus, to the extent that LLMD increases the risk for subsequent dementia in clinical studies, the predominant underlying pathologic process is likely to be AD. Our preliminary observation that $\mathrm{AD}$ was the most common neuropathologic diagnosis in LLMD subjects with dementia can be seen as consistent with this interpretation. If this preliminary association is confirmed, an important remaining question will be what accounts for the increased risk for $\mathrm{AD}$ in LLMD. For example, LLMD does not appear to be associated with increased rates of APOE4 (Butters et al, 2003), the only identified genetic risk factor for late-onset $\mathrm{AD}$.

The increased dementia risk in LLMD might be mediated by neuropathologic comorbidities. Both cerebrovascular lesions (Snowdon et al, 2003) and DLB pathology 
(Haroutunian et al, 2000; Serby et al, 2003) have been reported to be additive with $\mathrm{AD}$ pathology in generating cognitive symptoms. In none of our LLMD dementia subjects was $\mathrm{AD}$ the sole neuropathologic process present, as comorbid cerebrovascular lesions or DLB pathology were present in all cases. Cerebrovascular and DLB pathology were also present in an LLMD subject prior to any onset of dementia. In one LLMD subject with dementia, DLB was the only neuropathologic diagnosis. These findings are consistent with the possibility that cerebrovascular and DLB pathology may contribute to the manifestation of LLMD, and to the onset of dementia in LLMD subjects. Neuropathologic characterization of an enlarged sample of LLMD subjects with and without dementia, and including elderly control subjects with neither LLMD nor dementia, will be necessary to clarify the role of these pathologies in LLMD. Design of brainbanking procedures, as implemented in the our protocol, to allow for quantification of these pathologic features using unbiased stereologic methods may further enhance the ability to detect meaningful clinicopathologic correlations (Bussiere et al, 2002).

Alternatively, the mediator between LLMD and increased risk for $\mathrm{AD}$ may be a process not captured by conventional neuropathologic assessments. For example, Rajkowska et al (1999) reported that the density of reactive astrocytes in dorsolateral prefrontal cortex area 9 was highly correlated with age and duration of illness in subjects with major depression. Reactive astrocytes are integral components of the neuritic plaques of $\mathrm{AD}$, and appear to participate in the early development of these lesions (Pike et al, 1995; Styren et al, 1998). If reactive astrocytes are increased in LLMD, they may accelerate the process of development of neuritic plaques, and hence $\mathrm{AD}$.

In summary, we report preliminary results from an ongoing clinicopathologic study of LLMD. AD was the predominant neuropathologic diagnosis in LLMD subjects with dementia, though neuropathologic evidence of DLB and cerebrovascular disease were also frequent. These preliminary observations require confirmation in an expanded cohort of subjects, including subjects with neither LLMD nor dementia. Further quantitative studies directed at elucidating the mechanism(s) underlying the association of $\mathrm{AD}$ with LLMD are warranted.

\section{ACKNOWLEDGEMENTS}

This work was supported in part by USPHS grants MH66231, MH52247, MH01684, MH65416, and MH45156 from the National Institute of Mental Health, and P50 AG05133 from the National Institute of Aging. We thank the research staff of the Mental Health Intervention Research Center for Late Life Mood Disorders, the Program on Translational Neuroscience, and the Alzheimer Disease Research Center at the University of Pittsburgh.

\section{REFERENCES}

Alexopoulos GS, Meyers BS, Young RC, Mattis S, Kakuma T (1993). The course of geriatric depression with 'reversible dementia': a controlled study. Am J Psychiatry 150: 1693-1699.
American Psychiatric Association (1994). DSM-IV: Diagnostic and Statistical Manual of Mental Health Disorders. American Psychiatric Association: Washington, DC.

Becker JT, Boller F, Lopez OL, Saxton J, McGonigle KL (1994). The natural history of Alzheimer's disease: description of study cohort and accuracy of diagnosis. Arch Neurol 51: 585-594.

Braak H, Braak E (1995). Staging of Alzheimer's disease-related neurofibrillary changes. Neurobiol Aging 16: 271-284.

Bump GM, Mulsant BH, Pollock BG, Mazumdar S, Begley AE, Dew MA et al (2001). Paroxetine versus nortriptyline in the continuation and maintenance treatment of depression in the elderly. Depression Anxiety 13: 38-44.

Bussiere T, Friend PD, Sadeghi N, Wicinski B, Lin GI, Bouras C et al (2002). Stereologic assessment of the total cortical volume occupied by amyloid deposits and its relationship with cognitive status in aging and Alzheimer's disease. Neuroscience 112: 75-91.

Butters MA, Becker JT, Nebes RD, Zmuda MD, Mulsant BH, Pollock BG et al (2000). Changes in cognitive functioning following treatment of late-life depression. Am J Psychiatry 157: 1949-1954.

Butters MA, Sweet RA, Mulsant BH, Kamboh MI, Pollock BG, Begley AE et al (2003). APOE is associated with age-of-onset, but not cognitive functioning, in late-life depression. Int $J$ Geriatr Psychiatry 18: 1075-1081.

Butters MA, Whyte EM, Nebes RD, Begley AE, Dew MA, Mulsant $\mathrm{BH}$ et al (2004). The nature and determinants of neuropsychological functioning in late life depression. Arch Gen Psychiatry 61: $587-595$.

Conwell Y (1996). Outcomes of depression. Am J Geriatr Psychiatry 4: S34-S44.

Devanand DP, Sano M, Tang MX, Taylor S, Gurland BJ, Wilder D et al (1996). Depressed mood and the incidence of Alzheimer's disease in the elderly living in the community. Arch Gen Psychiatry 53: 175-182.

First MB, Gibbon M, Spitzer RL, Williams JBW (1997). Structured Clinical Interview for DSM-IV Axis I Disorders SCID I: Clinician Version, Administration Booklet. American Psychiatric Press: Washington, DC.

Folstein MF, Folstein SE, McHugh PR (1975). Mini mental state: a practical method for grading the cognitive state of patients for the clinician. J Psychiatr Res 12: 189-198.

Gearing M, Mirra SS, Hedreen JC, Sumi SM, Hansen LA, Heyman A (1995). The Consortium to Establish a Registry for Alzheimer's Disease (CERAD). Part X. Neuropathology confirmation of the clinical diagnosis of Alzheimer's disease. Neurology 45: 461-466.

Green RC, Cupples LA, Kurz A, Auerbach S, Go R, Sadovnick D et al (2003). Depression as a risk factor for Alzheimer disease: the MIRAGE study. Arch Neurol 60: 753-759.

Gurland BJ, Cross PS, Katz S (1996). Epidemiological perspectives on opportunities for treatment of depression. Am J Geriatr Psychiatry 4: S7-S13.

Hamilton M (1960). A rating scale for depression. J Neurol Neurosurg Psychiatry 23: 56-62.

Hamilton RL (2000). Lewy bodies in Alzheimer's disease: a neuropathological review of 145 cases using $\alpha$-synuclein immunohistochemistry. Brain Pathol 10: 378-384.

Haroutunian V, Serby M, Purohit DP, Perl DP, Marin D, Lantz M et al (2000). Contribution of Lewy body inclusions to dementia in patients with and without Alzheimer disease neuropathological conditions. Arch Neurol 57: 1145-1150.

Jorm AF, van Duijn CM, Chandra V, Fratiglioni L, Graves AB, Heyman A et al (1991). Psychiatric history and related exposures as risk factors for Alzheimer's disease: a collaborative re-analysis of case-control studies. EURODEM Risk Factors Research Group. Int J Epidemiol 20(Suppl 2): S43-S47.

Kokmen E, Beard CM, Chandra V, Offord KP, Schoenberg BS, Ballard DJ (1991). Clinical risk factors for Alzheimer's disease: a population-based case-control study. Neurology 41: 1393-1397. 
Kral VA, Emery OB (1989). Long-term follow-up of depressive pseudodementia of the aged. Can J Psychiatry 34: 445-446.

Krishnan KRR, Gadde KM (1996). The pathophysiologic basis for late-life depression. Am J Geriatr Psychiatry 4: S22-S33.

Lopez OL, Becker JT, Klunk WE, Saxton J, Hamilton RL, Kaufer D et al (2000a). Research evaluation and diagnosis of possible Alzheimer's disease over the last two decades. II. Neurology 55: 1863-1869.

Lopez OL, Becker JT, Klunk WE, Saxton J, Hamilton RL, Kaufer DI et al (2000b). Research evaluation and diagnosis of probable Alzheimer's disease over the last two decades. I. Neurology 55: 1854-1862.

Lopez OL, Hamilton RL, Becker JT, Wisniewski S, Kaufer DI, DeKosky ST (2000c). Severity of cognitive impairment and the clinical diagnosis of $\mathrm{AD}$ with Lewy bodies. Neurology 54: $1780-1787$.

Mattis S (1976). Mental status examination for organic mental syndrome in the elderly patient. In: Bellak L, Karasu TB (eds). Geriatric Psychiatry: A Handbook for Psychiatrists and Primary Care Physicians. Grune and Stratton: New York, NY.

McFarland C, Sweet RA, DeKosky ST, Houck PR, Mulsant BH, Pollock BG et al (2000). The establishment of a brain bank for the study of late-life depression: a feasibility study of factors facilitating consent. CNS Spectr 7: 816-821.

McKeith IG, Galasko D, Kosaka K, Perry EK, Dickson DW, Hansen LA et al (1996). Consensus guidelines for the clinical and pathologic diagnosis of dementia with Lewy bodies (DLB): report of the consortium on DLB international workshop. Neurology 47: 1113-1124.

McKeith IG, Perry EK, Perry RH (1999). Report of the second dementia with Lewy body international workshop: diagnosis and treatment. Neurology 53: 902-905.

Mezzich JE, Fabrega Jr H, Coffman GA, Haley R (1989). DSM-III disorders in a large sample of psychiatric patients: frequency and specificity of diagnoses. Am J Psychiatry 146: 212-219.

Mirra SS, Heyman A, McKeel D, Sumi SM, Crain BJ, Brownlee LM et al (1991). The consortium to establish a registry for Alzheimer's disease (CERAD). Part II. Standardization of the neuropathologic assessment of Alzheimer's disease. Neurology 41: 479-486.

Mulsant BH, Pollock BG, Nebes R, Miller MD, Sweet RA, Stack J et al (2001a). A twelve week double-blind randomized comparison of nortriptyline and paroxetine in older depressed inpatients and outpatients. Am J Geriatr Psychiatry 9: 406-414.

Mulsant BH, Sweet RA, Rosen J, Pollock BG, Zubenko GS, Flynn T et al (2001b). A double-blind randomized comparison of nortriptyline plus perphenazine versus nortriptyline plus placebo in the treatment of psychotic depression in late life. J Clin Psychiatry 62: 597-604.

Nebes RD, Pollock BG, Houck PR, Butters MA, Mulsant BH, Zmuda MD et al (2003). Persistence of cognitive impairment in geriatric patients following antidepressant treatment: a rando- mized, double-blind clinical trial with nortriptyline and paroxetine. J Psychiatr Res 37: 99-108.

O'Brien J, Thomas A, Ballard C, Brown A, Ferrier N, Jaros E et al (2001). Cognitive impairment in depression is not associated with neuropathologic evidence of increased vascular or Alzheimer-type pathology. Soc Biol Psychiatry 49: 130-136.

Overall JE, Gorham DR (1962). The brief psychiatric rating scale. Psychol Rep 10: 799-812.

Pike CJ, Cummings BJ, Cotman CW (1995). Early association of reactive astrocytes with senile plaques in Alzheimer's disease. Exp Neurol 132: 172-179.

Rajkowska G, Miguel-Hidalgo JJ, Wei J, Pittman SD, Meltzer HY, Overholser JC et al (1999). Morphometric evidence for neuronal and glial prefrontal cell pathology in major depression. Soc Biol Psychiatry 45: 1085-1098.

Reynolds III CF, Frank E, Perel JM, Imber S, Cornes C, Miller MD et al (1999). Nortriptyline and interpersonal psychotherapy as maintenance therapies for recurrent major depression. JAMA 281: 281-293.

Royall DR, Mahurin RK, Gray KF (1992). Bedside assessment of executive cognitive impairment: the executive interview. $J \mathrm{Am}$ Geriatr Soc 40: 1221-1226.

Serby M, Brickman AM, Haroutunian V, Purohit DP, Marin D, Lantz $M$ et al (2003). Cognitive burden and excess Lewy-body pathology in the Lewy-body variant of Alzheimer disease. Am J Geriatr Psychiatry 11: 371-374.

Snowdon DA, Greiner LH, Mortimer JA, Riley KP, Greiner PA, Markesbery WR (2003). Brain infarction and the clinical expression of Alzheimer disease. The nun study. JAMA 277: 813-817.

Speck CE, Kukull WA, Brenner DE, Bowen JD, McCormick WC, Teri L et al (1995). History of depression as a risk factor for Alzheimer's disease. Epidemiology 6: 366-369.

SPSS Inc. SPSS for Windows 10.0. Chicago, 1999.

Styren SD, Kamboh MI, DeKosky ST (1998). Expression of differential immune factors in temporal cortex and cerebellum: the role of $\alpha$-1-antichymotrypsin, apolipoprotein $\mathrm{E}$, and reactive glia in the progression of Alzheimer's disease. J Comp Neurol 396: 511-520.

Sweet RA, Hamilton RL, Lopez OL, Klunk WE, Wisniewski SR, Kaufer DI et al (2000). Psychotic symptoms in Alzheimer's disease are not associated with more severe neuropathologic features. Int Psychogeriatr 12: 547-558.

Thomas AJ, Ferrier IN, Kalaria RN, Perry RH, Brown A, Oakes D et al (2001). A neuropathological study of vascular factors in late-life depression. J Neurol Neurosurg Psychiatry 70: 83-87.

van Duijn CM, Clayton DG, Chandra V, Fratiglioni L, Graves AB, Heyman A et al (1994). Interaction between genetic and environmental risk factors for Alzheimer's disease: a reanalysis of case-control studies. EURODEM Risk Factors Research Group. Genet Epidemiol 11: 539-551. 